\title{
Colonos y soldados en el Oriente Helenístico
}

\author{
Adolfo J. DOMíngez Monedero */**
}

Este artículo estudia las formas que asume el asentamiento de soldados en el mundo helenístico. En primer lugar, se estudia la época de Alejandro Magno en cuanto que precedente; en efecto, Alejandro ha utilizado en gran medida a sus soldados para fundar nuevas colonias, que son un medio de proteger y defender sus conquistas. Este procedimiento ha sido igualmente empleado por sus sucesores, los reyes helenísticos. Aquí estudio ante todo los reinos Seléucida y Tolemaico, haciendo especial hincapié en los diferentes métodos de los que cada uno de ellos se ha servido, y los distintos fines que debía alcanzar cada una de sus respectivas políticas de asentamiento. Del mismo modo, en cada uno de los tres casos abordados me detengo ante todo en las relaciones entre macedonios, griegos, indígenas y no griegos en general en las nuevas fundaciones. Como conclusión, se resalta el sentido general de todo el proceso en la conformación del mundo helenístico.

COLONISTS AND SOLDIERS IN THE HELLENISTIC EAST. (ABSTRACT)

This paper analyzes the ways in which the settlement of soldiers has been accomplished in the Hellenistic world. Firstly, I study the age of Alexander the Great as a precedent; Alexander has greatly used his soldiers in the foundation of new colonies as a way to protect and defend his

\footnotetext{
* Universidad Autónoma de Madrid.

Este trabajo se realiza dentro del Proyecto de Investigación PS92-0024, financiado por la $D G / C Y T$.

** Ciclo Guerra y Religión en el Próximo Oriente y Egipto.
} 
conquests. This procedure has been also used by his successors, the Hellenistic kings. I study mainly the Seleucid and the Ptolemaic Kingdoms, stressing the different ways each of them has used, and the different purposes of their different settlement politics. In the three cases dealt the relations between Macedonians, Greeks, Natives and non-greeks in general in the new foundations are underlined. As a conclusion the overall meaning of all the process in the shaping of the Hellenistic world is emphasized.

\section{INTRODUCCIÓN}

Paz a cambio de territorios... Esta proclama que goza en la actualidad de un evidente prestigio como medio para tratar de solventar las diferencias entre determinados estados del Oriente Medio podríamos parafrasearla y, cambiando radicalmente su significado, aplicarla a lo que fue una de las situaciones habituales en el Próximo Oriente y el Egipto Helenísticos: guerra a cambio de territorios. En efecto, en el mundo helenístico, y aparte de las tropas mercenarias, a las que no me voy a dedicar en el presente trabajo y quizá a las tropas indígenas, los principales contingentes militares eran los compuestos por tropas de origen griego y macedonio y estas tropas procedían, en buena medida, del propio territorio controlado por los diferentes reinos helenísticos. La obligación militar de estos individuos, por ende, venía dada, al menos en el Egipto Lágida, por el hecho de que eran titulares de lotes de tierra, kleroi, de los que obtenían los recursos suficientes como para conformar un grupo selecto dentro de las complejas estructuras sociales de las monarquías helenísticas. Como afirma Will, «la práctica de la colonización militar se impone tanto por consideraciones político-estratégicas (ocupación y pacificación de los paises conquistados, mantenimiento del orden, defensa de las fronteras) cuanto por consideraciones económicas (al permitir con la distribución de parcelas de tierra reducir los gastos en numerario)" '. De cómo y por qué surgieron, cómo se organizaban estas comunidades y cómo las mismas contribuyeron a dotar de soldados a los ejércitos helęnísticos versará el presente artículo.

Aunque en la medida de lo posible procuraré ir precisando los términos, hay que señalar, empero, como dato previo que es sumamente difícil en muchas ocasiones distinguir las "colonias militares" estríctamente hablando (katoikial) de las poleis o ciudades; ambas pueden haber coexistido

WILL, E., "Guerre, acculturation et contre-acculturation dans le monde hellenistique», Polis, núm. 1, (1988), pág. 41. 
contemporáneamente, pero parece igualmente fuera de duda que muchas katoikias han acabado por convertirse en ciudades.

\section{LOS PRECEDENTES. LAS FUNDACIONES DE ALEJANDRO MAGNO}

La tendencia a fundar ciudades greco-macedonias en los territorios conquistados se inicia ya con el propio Alejandro Magno y es su acción la que posibilita la de los monarcas que le suceden en las distintas partes del imperio por él ganado; en efecto, como afirma Plutarco en su opúsculo Sobre la Fortuna o Virtud de Alejandro, "Alejandro ... fundó más de setenta ciudades en pueblos bárbaros y sembró Asia de magistraturas griegas y se impuso así sobre su modo de vivir salvaje e incivilizado ... Los que fueron conquistados por Alejandro son más felices que los que escaparon a su mano ... (y) no estarían civilizados si no hubieran sido dominados. Egipto no poseería Alejandría ni Mesopotamia Seleucia ni Sogdiana Proftasia ni India Bucefalia ni el Cáucaso tendría una ciudad griega vecina. Con estas fundaciones se extinguió lo salvaje y lo peor se habituó a lo mejor y cambió de signo» (Plutarco, Mor., 328 E-F-329 A).

El número de setenta colonias es, seguramente, excesivo. Tscherikower, en su obra clásica sobre las fundaciones helenísticas ${ }^{2}$, mencionaba 34 ciudades, de las cuales la mitad al menos eran dudosas; en cualquier caso, y aunque el número se redujese a diecisiete no deja de ser una cifra apreciable. Hammond observa cómo buena parte de esas fundaciones, en las que iban a vivir individuos heridos procedentes de su ejército, así como mercenarios licenciados, ejercían funciones de guarnición y vigilancia de rutas de comunicación estratégica, aun antes de la decisiva batalla de Gaugamela ${ }^{3}$, por lo que la función militar de las mismas queda clara desde el inicio. Naturalmente, de todas las Alejandrías fundadas por Alejandro o atribuidas a él, es sin duda la que se estableció en Egipto la mejor conocida y la destinada a un futuro más esplendoroso; no obstante, la misma no parece especialmente significativa del tipo al que aquí me estoy refiriendo ya que, si creemos a Hammond, «Alejandro estaba creando no una pequeña ciudad de tipo colonial o de tipo acrópolis, sino una gran ciudad macedonia» 4; por otro lado, es posible que después de esta Alejandría, y aunque

TSCHERIKOWER, V., Die hellenistischen Städtegründungen von Alexander dem Grossen bis auf die Römerzeit. (Philologus, supl. 19). Leipzig, 1927, (Reimpr. 1973), págs. 145-146.

3 Hammond, N.G.L., Alejandro Magno. Rey, general y estadista. Madrid, Alianza Editorial, 1992, pág. 220.

Ibidem, pág. 179. 
había muchas otras ciudades que llevaban este nombre y que no eran fundaciones del propio Alejandro, éste haya mitigado su política de fundaciones hasta haber llegado al Asia Central; Tscherikower pensaba (frente a la opinión recién recogida de Hammond) que antes de la llegada a Susa Alejandro no habría podido emprender una amplia política de colonización, habida cuenta las cifras que se manejan para sus efectivos militares; a partir de ellos, y para dicho autor, "puesto que fueron ciertamente los veteranos macedonios y los mercenarios griegos el elemento principal del que se sirvió Alejandro para asentarlos en colonias, la consecuencia destaca por sí misma: Alejandro pudo poner en marcha su actividad colonizadora sólamente durante la segunda parte de su expedición» y nunca antes de la victoria definitiva sobre los persas y la muerte de Darío ${ }^{5}$.

La función defensiva y estratégica de muchas de las fundaciones helenísticas, empezando por las atribuidas al propio Alejandro puede verse a partir de un pasaje de Polibio en el que asegura que «(Media) está rodeada de ciudades griegas por la precaución de Alejandro: así se ve defendida contra los bárbaros que la circundan. La única ciudad no griega es Ecbatana, edificada en la parte septentrional de Media. Esta urbe detenta el gobierno de las regiones asiáticas del Ponto Euxino y de Meótide» (Polibio, x, 27, 3-4); a pesar de la afirmación de Polibio, sin embargo, es harto probable que esta política sea debida más bien a la actividad de los dos primeros Seléucidas ${ }^{6}$ aunque acaso no sea rechazable que la idea pudiera haber correspondido al propio Alejandro.

Un análisis más detallado de aquellas fundaciones que posiblemente sí puedan atribuirse a Alejandro muestra a las claras su carácter estratégicomilitar; así, por ejemplo, la fundación de Alejandría Escate, tal y como la transmite Arriano (Anábasis, IV, 1, 3-4): «Pensaba Alejandro fundar una ciudad a orillas del Tanais y darle su mismo nombre, pues el lugar le parecía muy propicio para que la ciudad prosperase, muy idóneo su asentamiento ante un eventual ataque contra los escitas, y un buen bastión defensivo de la región contra las correrías de los bárbaros que habitaban al otro lado del río. Además, pensaba que la ciudad se haría importante por el número de colonos y el esplendor de su nombre». Igualmente, Diodoro $(\mathrm{xVII}, \kappa \delta$ ) en la lista de contenidos de su libro XVII asegura que va a tratar de «cómo castigó a los bactrianos, redujo a los sogdianos por segunda vez y fundó ciudades estratégicamente situadas para castigar a los que hicieran defección».

\footnotetext{
TScherikower, V., Op. cit. págs. 140-142. Ibidem, pág. 145.
} 
La fundación de Alejandría en Margiana, no visitada nunca por Alejandro, muestra también preocupaciones defensivas; tal y como informa Curcio, "habiendo pasado después los ríos Oco y Oxo, llegó a la ciudad de Margiana. A su alrededor fueron escogidos seis lugares para emplazar en ellos fortalezas, dos orientadas al mediodía y cuatro al oriente: entre unas y otras había poco espacio, para no ir a buscar demasiado lejos el mutuo auxilio: entonces fueron como frenos para los pueblos a quienes ellas mandaron» (Curcio, VII, 10, 15-16). Además, Arriano da noticias en varias ocasiones de fundaciones y establecimiento de guarniciones por parte de Alejandro, prácticamente al paso de su ejército; entre ellas, destacan los casos de Alejandría en el Tanais (Anábasis, IV, 1, 3-4), Alejandría en Rambacia (Anábasis, VI, 21, 5), la capital de Musícano (Anábasis, vi, 15, 7), o Arigeo (Anábasis, IV, 24, 7); con respecto a esta última dice nuestro autor: «le pareció a Alejandro ésta una ciudad ubicada en un lugar muy estratégico, y por ello encargó a Crátero que la fortificara y repoblara con los habitantes vecinos de aquella tierra que quisieran instalarse en ella, así como con los soldados del ejército que hubieran quedado inútiles para el servicio de armas", pasaje que nos indica cómo aprovecha Alejandro tanto a los nativos como, sobre todo, a aquellos miembros de su expedición que hubiesen resultado heridos o hubiesen caído enfermos durante sus campañas.

Así, podemos afirmar que las preocupaciones estratégicas fueron fundamentales para Alejandro en la planificación de sus fundaciones estando también presente la idea de protección y defensa de los territorios conquistados y de los límites de su imperio ${ }^{7}$; no obstante, otro tipo de preocupaciones como las comerciales no debieron de estar ausentes, aunque aquí no entraremos en ellas ${ }^{8}$.

Suele ser habitual que Alejandro encargue a sus oficiales de confianza, generalmente hetairoi suyos, todas las tareas necesarias para la fundación; en la misma suelen estar representados, en mayor o menor medida, tres elementos: veteranos macedonios, mercenarios griegos y población indigena; caso aparte son las guarniciones macedonias, que no constituyen asentamiento en el sentido estricto del término ${ }^{9} \mathrm{y}$ de la que un buen ejemplo podría ser la establecida en la isla de Ícaro, la actual Failaka, en la cabecera del Golfo Pérsico ${ }^{10}$; en todo caso y como este mismo ejemplo

Ibidem, págs. 150-151.

Ibidem, págs. 150-152.

Ibidem, págs. 190-191.

10 Parece hoy día bastante más probable, a partir tanto de la epigrafía como de los testimonios arqueológicos que en Failaka haya habido una pequeña guarnición griega bien desde la 
muestra también las guarniciones militares recibirían tierras para su cultivo, aunque no en propiedad, ya que ésta seguía estando en manos del rey.

Se ha debatido en ocasiones acerca de la voluntariedad o no del asentamiento de griegos en sus nuevas fundaciones y da la impresión, en general, de que la misma era muy limitada; como afirmaba Tscherikower, "si Alejandro hubiese permitido a sus soldados la posibilidad de elegir libremente, apenas habría fundado más de un par de ciudades " ${ }^{11}$ y Justino informa sobre la existencia de "colonias de castigo", especialmente en el caso de las fundadas en Bactriana y Sogdiana: «Fundó siete ciudades, en las que estableció a aquellos que habían mostrado en el ejército comportamiento sedicioso" (Justino, XII, 5, 13); por otro lado, Arriano transmite un discurso de Ceno en el que se afirma: «Del resto de los griegos, a unos los has asentado en las ciudades que has ido fundando, aunque no todos están en ellas contentos" (Arriano, Anábasis, $\mathrm{VI}, 27,5$ ); Diodoro nos proporciona también una interesante noticia cuando nos narra las consecuencias de las graves heridas que sufrió Alejandro durante el asalto a la Roca Sogdiana: «Entonces los griegos asentados en Bactria y Sogdiana, que soportaban desde hacía tiempo muy mal este asentamiento entre pueblos bárbaros, al llegarles ahora el rumor de que el rey, que había resultado herido, había muerto, se levantaron contra los macedonios. Se reunieron unos tres mil y emprendieron el regreso a casa en medio de grandes penalidades. Más tarde, después de la muerte de Alejandro, fueron aniquilados por los macedonios" (Diodoro, xVII, 99, 5-6); esto mostraría en parte la extensión de la política de asentamientos llevada a cabo por Alejandro y en parte también que no todos los asentados lo habían hecho totalmente de grado; esto mismo también ocurrió, en mayor extensión, tras la muerte (en este caso auténtica) de Alejandro (Diodoro, xvIII, 7).

época de Alejandro como sugieren algunos autores, bien desde la época de los primeros Seléucidas opinión esta última hoy mayoritaria. En un momento ulterior, a finales del siglo ill-inicios del siglo ॥ a.c. esa guarnición o bien sería reforzada o bien reestablecida, como consecuencia de la nueva política iniciada por Antíoco III y proseguida por Antíoco IV. Recientes aproximaciones a la Failaka helenística en SALLES, J.F. «The Arab-Persian Gulf under the Seleucids», en KuHRT, A. , SHERWINWHITE, S., Hellenism in the East. The interaction of Greek and non-Greek civilizations from Syria to Central Asia. Londres, 1987, págs. 75-109; CALLOT, O. «Failaka à l'époque hellénistique", en FAHD T. (edit.). L'Arabie pré-islamique et son environment historique et culturel. Leiden, 1989, págs. 127143; en último lugar, GACHET, J.; SALLES, J.F. «Failaka, Koweit» en FINKBEINER U. (edit.). Materialen zur Archäologie der Seleukiden- und Partherzeit im südlichen Babylonien und im Golfgebiet. Tubinga, 1993. págs. 59-85. Sobre la epigrafía griega de Failaka ROUECHE, S.; SHERWIN-WHITE, S.M. «Some aspects of the Seleucid Empire: the Greek inscriptions from Failaka in the Arabian Gulf ", Chiron, núm. 15, (1985), págs. 1-39. Frente a esta visión, hoy predominante, de considerar Failaka únicamente como guarnición militar, Cohen argumentó a favor de considerarla una colonia militar típica; ct. COHEN, G.M. The Seleucid colonies. Studies in Founding, Administration and Organization. (Historia Einzelschr., 30). Wiesbaden, 1978. págs. 42-44. Hoy día queda claro que el asentamiento no alcanzó nunca el estatus de polis y que sus tierras formaban parte de la chora basilike.

11 TSCHERIKOWER, V., Op. cit., pág. 192. 
Los canditatos más idóneos para formar la población de las nuevas ciudades eran los veteranos y los heridos de guerra que no deben ser considerados como un elemento totalmente inútil para todo servicio; aun cuando incapaces de seguir soportando las fatigas y penalidades de las campañas de Alejandro, sí estaban capacitados para desempeñar las tareas militares, relativamente ligeras, en las ciudades en que eran asentados, tales como la guarnición de las mismas o la supresión de revueltas bárbaras.

La utilidad que tenían para Alejandro estas fundaciones era doble: por un lado reforzaba el componente militar en las colonias y, por otro, se despreocupaba de sus veteranos a los que, de lo contrario, tendría que haber reenviado a Europa, lo que no era nada fácil; no obstante, muchos de estos veteranos prefirieron, a pesar de todo, regresar a su patria (Arriano, Anábasis, III, 29, 5; VI, 17, 3; VII, 12, 1). La necesidad de los indígenas en las nuevas fundaciones era evidente, puesto que eran ellos, en especial las mujeres, las que contribuirían a la perpetuación de la ciudad ${ }^{12}$. Las fuentes, en todo caso, aluden a la existencia de matrimonios mixtos incluso entre individuos que no se establecen definitivamente en Asia; así por ejemplo, Arriano (Anábasis, vil, 12, 1) narra lo siguiente: «Desde allí (Opis) se organizó la expedición de los macedonios que voluntariamente querían regresar por haber quedado inútiles para la guerra, por su edad o por alguna otra circunstancia. Este contingente resultó ser de unos diez mil hombres. Alejandro les pagó el salario devengado hasta ese mismo día, y a ello añadió la cantidad que les correspondía hasta el día que llegaran a casa de regreso. Aún añadió, aparte de esta soldada, un talento para cada uno de sus hombres. Les aconsejó que dejaran allí con él a los hijos que hubieran tenido con mujeres asiáticas, a fin de evitar que a su regreso surgiera alguna querella entre estos hijos nacidos de otras tribus y bárbaras, con los que habían dejado en Macedonia y sus madres; Alejandro se comprometió a ocuparse de ellos y educarlos como macedonios en todos los aspectos, y a hacerlos disciplinados en los asuntos de la milicia; una vez que se hicieran hombres, él mismo los llevaría a Macedonia y los entregaría a sus padres».

12 Ibidem, págs. 193-194; esta necesidad es, por ende, percibida en todo proceso colonizador griego, incluyendo los de época arcaica. A tal respecto me limitaré a aludir a mi artículo, DOMínguez, A.J., "Consideraciones acerca del papel de la mujer en las colonias griegas del Mediterráneo Occidental" en Actas de las V Jornadas de Investigación Interdisciplinaria, Madrid, Universidad Autónoma de Madrid, 1986, págs. 143-152, en el que planteó las principales posturas mantenidas al respecto. 


\section{LAS FUNDACIONES DE LOS REYES HELENÍSTICOS.}

Tras la muerte de Alejandro y los complejos acontecimientos que tienen lugar como consecuencia de ella, se abre el camino para la formación de los estados helenísticos y ya monarcas como Antígono I emprenden una decidida política de nuevas fundaciones tanto en Asia Menor como en la Siria septentrional en las que asienta a buena parte de sus veteranos ${ }^{13}$; sin embargo, se observan en las fundaciones de Antígono I algunas diferencias con respecto a las de Alejandro: en primer lugar, que se trata siempre de ciudades, lo que no se da en todas las ocasiones con Alejandro; en segundo lugar, se trata de fundaciones de tipo propiamente "helenístico" y no exclusivamente macedonias ${ }^{14}$.

Es tras la definitiva consolidación de los estados helenísticos cuando podemos empezar a realizar una valoración de conjunto de las políticas a este respecto seguidas por ellos, que terminaría llegando al extremo, como observa Launey, de que la casi totalidad de los macedonios que combaten en los ejércitos Lágidas y Seléucidas y también en los atálidas, procede no de Macedonia, sino de las colonias militares establecidas por los soberanos helenísticos ${ }^{15}$.

\subsection{Los Seléucidas}

Cohen distingue, entre las fundaciones Seléucidas, tres tipos: las colonias civiles, constituidas por individuos trasladados directamente desde sus lugares de residencia anterior, las guarniciones militares dispersas por el imperio y, sobre todo, las colonias militares, término que para dicho autor significa "asentamiento originariamente compuesto de soldados retirados o en reserva» ${ }^{16}$; el término que se utiliza para referirse a ellas es el de katoikia. Para Tarn y Griffith, en su obra clásica sobre la civilización helenística, «eran los hombres de los kleroi, los clerucos, quienes constituían la espina dorsal de los ejércitos Seléucidas, las falanges greco-macedonias; era proverbial su lealtad hacia el Seléucida reinante, lo que prueba que se les tenía en buena situación» ${ }^{17}$.

TSCHERIKOWER, V. Op. cit, págs. 154-162.

Ibidem, págs. 160-161.

LAUNeY, M. Recherches sur les armées hellénistiques, t. I, París, De Boccard, 1949, pág. 331.

COHEN, G.M. Op. cit., pág. 4.

i7 TARn, W.W.; GRIFFIth, G.T. La civilización helenística, 3ae ed. Méjico, FCE., 1952, págs. 109-110. 
Prácticamente todos los autores están de acuerdo en que el auge y principal desarrollo de la política colonial en el Reino Seléucida tuvo lugar, como muchos otros aspectos, durante el reinado de Seleuco i y Antíoco I, por más que otros monarcas pudieran haber aportado algo al respecto ${ }^{18}$; en cualquier caso, el número total de colonias fundadas por los Seléucidas debe de hallarse cerca de las setenta ${ }^{19}$.

Acerca del gran número de fundaciones que llevó a cabo Seleuco Nicator disponemos de un revelador pasaje de Apiano: «Fundó ciudades a lo largo de todo su imperio: a dieciséis, les dio el nombre de Antioquía en recuerdo de su padre; a cinco, el de Laodicea por su madre; a nueve, les puso su nombre, y a cuatro, los de sus esposas: tres Apamea y una sola Estratonicea. Las más famosas de ellas, incluso en la actualidad, son las dos Seleucias, la una junto al mar y la otra a orillas del Tigris, la Laodicea de Fenicia, la Antioquía que está al pie del monte Líbano y la Apamea de Siria. A las demás ciudades les dio nombres de Grecia o Macedonia, o bien en recuerdo de alguna de sus hazañas o en honor del rey Alejandro. Por esta razón, existen en Siria y en los países bárbaros del interior de Asia muchos nombres de ciudades griegas y macedonias: Berrea, Edesa, Perinto, Maronea, Calípolis, Acaya, Pela, Oropo, Anfípolis, Aretusa, Astaco, Tegea, Calcis, Larisa, Herea, Apolonia; en Partia están Sotira, Calíope, Caris, Hecatómpilo y Acaya; en la India, Alejandrópolis; y en Escitia Alejandréscata. En recuerdo de las victorias del propio Seleuco están Niceforio, en Mesopotamia, y Nicópolis en Armenia, la más próxima a Capadocia». (Apiano, Siria, 57). Como ocurría con las fundaciones de Alejandro, cuya cifra fue extraordinariamente magnificada, también en esta lista hay ciudades que no corresponden a la época a la que las atribuye Apiano: la Nicópolis de Armenia corresponde a Pompeyo; Sotira y Acaya, además de estar en Ariana y no en Partia parecen corresponder a Antíoco y no a Seleuco y Alejandréscata y Alejandrópolis en la India deben de ser fundaciones del propio Alejandro; por último, las ciudades de nombre macedonio no tienen por qué haber sido fundaciones de Seleuco sino más bien asentamientos macedonios o simples nombres de este origen dado a localidades indígenas ${ }^{20}$.

18 TSCHERIKOWER, V. Op. cit., pág. 165; cf. COHEN, G.M. Op. cit., pág. 11, que incluye, además de a Seleuco i Nicator y Antioco I Soter a Antioco "Theos, a Antíoco ill el. Grande y a Antioco IV EPIFANES, aunque reconoce que son los dos primeros los que fundaron la mayor parte de colonias.

19 Cohen, G.M., Op. cit., pág. 11. Vid. además Grainger, J.D. The cities of Seleukid Syria. Oxford, Clarendon Press, 1990; id., Hellenistic Phoenicia. Oxford, O.U.P., 1991.

20 Tscherikower, V. Op. cit., pág. 166. 
También se refiere a esta política de Seleuco Nicator Libanio cuando afirma: "Los otros reyes han sido exaltados por destruir ciudades existentes; él, por el contrario, por organizar ciudades que aún no existían. Ha establecido tantas sobre la tierra que habría bastantes para llevar los nombres de las ciudades de Macedonia así como los nombres de los miembros de su familia; hubo muchas ciudades que compartieron el nombre de una sola persona, hombre o mujer. Además, si alguien quisiera compararle con los atenienses y los milesios, de los que se dice que han enviado el mayor número de colonias, aparecería como un colonizador mayor porque superó a cada una de ellas en la magnitud de sus trabajos ya que cada una de sus ciudades valia más que diez de las suyas. Puede irse a Fenicia a ver sus ciudades, puede irse a Siria y ver más y mayores ciudades suyas. Extendío esta noble actividad hasta el Éufrates y el Tigris; y rodeando Babilonia con ciudades, las extendió por todas partes, incluso por Persia, Por fin, no hubo lugar adecuado para recibir una ciudad que quedase desierto; es más helenizando a los bárbaros, acabó con ellos" (Libanio, Orat., XI, 101-103).

Aun cuando para Antíoco I no se dispone de un panorama semejante, parece bastante posible que no fue a la zaga de su padre en cuanto a la fundación de nuevas ciudades y es posible que algunas de las que Apiano le atribuye a Seleuco sean, de hecho, fundaciones suyas, especialmente las más al Oriente, puesto que Antíoco fue ya rey de esa zona en vida de su padre ${ }^{21}$. Otros reyes Seléucidas no parecen haber llevado a cabo políticas semejantes y el único de ellos que parece haber dado su nombre a numerosas fundaciones es Antíoco IV, aunque parece poco probable que fundase realmente ciudades, sino que más bien dotaría a ciudades ya helenizadas en mayor o menor medida de determinados derechos y privilegios propios de ciudades griegas, de los que acaso no disfrutasen con anterioridad, tales como la acuñación de moneda, aun cuando parece bastante probable que su organización interna fuese ya de ciudades griegas ${ }^{22}$; también reconstruiría ciudades anteriores a él y afectadas por algún desastre natural, como la antigua Alejandría del Tigris, tal y como nos informa Plinio: «La ciudad de Charax se sitúa en la parte más interna del Golfo Pérsico desde el que se proyecta el país llamado Arabia Felix. Se halla sobre una elevación arificial entre el Tigris a la derecha y el Euleo a la izquierda, en el punto en el que ambos ríos confluyen, y el sitio mide dos millas de anchura. La ciudad original fue fundada por Alejandro Magno

21 Ibidem, págs. 166-168.

22 Ibidem, págs. 176-177; cf. COHEN, G.M., Op. cit., págs. 13-14. 
con colonos traídos de la ciudad real de Durine, que fue destruida por entonces y con soldados inválidos de su ejército que fueron dejados allí. Había dado órdenes de que fuese llamada Alejandría, y un barrio que había asignado especialmente a los Macedonios debía llamarse Pellaeum en recuerdo del lugar de su nacimiento. Esta ciudad fue destruida por los ríos, pero fue posteriormente restaurada por Antíoco, el quinto de los reyes, que le dio su propio nombre; y cuando posteriormente hubo sufrido también daños fue reconstruida y llamada con su nombre por Spaosines, hijo de Sagdodonaco, rey de los árabes vecinos, del que afirma erróneamente Juba que fue un sátrapa de Antíoco; construyó diques para la protección de la ciudad y elevó el nivel del terreno adyacente por un espacio de más de seis millas en longitud y un poco menos en anchura. Originalmente se hallaba a una distancia de 1,25 millas de la costa y tenía un puerto propio, pero cuando Juba publicó su obra estaba a 50 millas tierra adentro; su distancia actual de la costa ha sido establecida por enviados árabes y por nuestros propios comerciantes que han llegado de aquel lugar en 120 millas". (Plinio, NH., VI, 138-140); como puede verse, esta práctica caló también entre los sucesores de los Seléucidas en el control del Próximo Oriente ${ }^{23}$.

Un caso específico de establecimientos es el constituido por las katoikias macedonias en Asia Menor y que en buena medida pueden corresponder a Antíoco I y a Antíoco II. Según Tscherikower «una katoikia militar es un asentamiento de soldados que no posee ningún derecho de ciudad y cuyos miembros han recibido parcelas de tierra ( $\kappa \lambda \tilde{\eta} \rho \circ)$ para su cultivo

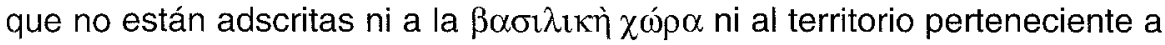
ninguna ciudad»; muchos de estos centros acabaron alcanzando con el tiempo el estatus de ciudades. Este tipo de establecimiento está presente en todo el Oriente hasta el Indo y en muchos casos se trata de ciudades orientales en las que los diferentes reyes, ya desde la época de Alejandro habían implantando estos asentamientos o habían tan sólo colocado guarniciones. En las fuentes posteriores muchos de estos centros aparecen como fundaciones de macedonios, tales como, por ejemplo, Ichnai y Dura, que Isidoro de Cárax considera Makedonon ktismata ${ }^{24}$. También Tscherikower era de la opinión de que la gran cantidad de ciudades que llevan topónimos de tipo macedonio (él contaba unas treinta) deben su nombre a que el propio ejército macedonio tendía a llamar a sus nuevos

23 Sobre la ciudad de Alejandría del Tigris-Antioquía-Spasinou Charax y su región, vid. Bowersock, G.W. «La Mésène (Maisân) antonine» en FAHD, T (edit.), Op. cit., págs. 159-168.

24 Tscherikower, V., Op. cit., págs. 12t-122. 
lugares de residencia con nombres que procedían de su patria originaria, como mostraría también la tendencia a bautizar con nombres greco-macedonios ríos, montañas y regiones enteras; es más, según dicho autor, «fueron los soldados macedonios los que dieron el nombre de su patria a sus nuevas colonias", si bien es bastante probable que esos nombres no tuvieran, generalmente, ningún carácter oficial como probaría el que en muchos casos fuesen ulteriormente sustituidos por nombres «dinásticos» 25 .

En el caso de las katoikias en Asia Menor Tscherikower creía que más que una función estrictamente militar, las mismas tenían como finalidad básica el proporcionar a los veteranos tierras para cultivar a fin de que de ellas obtuviesen los recursos necesarios para vivir; como consecuencia de ello, el asentamiento resultante era de tipo aldeano, sin que pudiese jugar ningún tipo de papel político; no obstante, su organización interna era de tipo puramente militar, puesto que sus habitantes se llamaban a sí mismos soldados (stratiotai) y se hallaban bajo el mando de sus oficiales (hegemones) y el rey podía exigirles el cumplimiento de sus obligaciones militares; sin embargo, es posible que estos deberes apenas fuesen exigidos puesto que, como opina el mismo autor, una katoikia a cuyos habitantes se les exigiese con frecuencia este tipo de servicio apenas habría durado muchos años, frente a lo que parece haber sido la norma, ya que aún en época tardorromana sigue habiendo ciudades, procedentes de antiguas katoikias, que continúan acuñando moneda con el epígrafe MAKE $\triangle O N \Omega N$; los motivos que sugiere Tscherikower para estas katoikias van desde la explotación de tierras reales, la proximidad de centros comerciales, la calidad del terreno, etc.; que ocasionalmente ocupasen territorios de importancia estratégica sería puramente casual; también sus promotores son difíciles de establecer y pueden ir desde Antíoco I y II hasta monarcas posteriores, puesto que una demanda generalizada de los soldados debe de haber sido disponer de tierras tras su retiro del servicio activo ${ }^{26}$. Cohen es de la opinión de que la continuidad de las guerras en Asia Menor durante buena parte del siglo III y el temprano predominio de los Atálidas, impidieron que estas katoikias se desarrollaran hasta convertirse en ciudades propiamente dichas, por lo que siguieron conservando su organización colonial inicial durante largo tiempo después de su fundación ${ }^{27}$.

Parece fuera de duda que todas las colonias macedonias habían sido originariamente asentamientos de soldados; a partir del conocimiento de

\footnotetext{
Ibidem, págs. 123-124.

Ibidem, págs. 173-174.

COHEN, G.M., Op. cit., págs. 10-11.
} 
las katoikias militares macedonias asentadas por los Seléucidas en Asia Menor podría sugerirse que el étnico «Macedonios» vendría a equivaler a tropas militares; la extensión de asentamientos macedonios viene a coincidir con las zonas en las que han estado activos los reyes con su ejército; ya las fundaciones alejandrinas habían contado como habitantes a macedonios eméritos, y todas las ciudades de Siria y Mesopotamia que llevan nombres macedonios deben de haber sido originariamente katoikias macedonias y, como decíamos anteriormente, conservaron durante mucho tiempo recuerdo de su origen; por ejemplo, los habitantes de Carras, aún en época de Pompeyo, unos 250 años después de su funda-

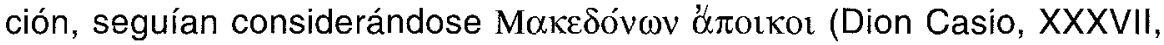
5). Tanto en Mesopotamia, como en Asia Menor y Egipto los katoikos fueron originariamente individuos sin tierras, establecidos con fines agrícolas. Teniendo en cuenta que el ejército macedonio se reclutaba básicamente entre campesinos, resulta fácil comprender que los asentamientos macedonios en Siria y Mesopotamia constituyeron pronto grandes comunidades agrarias, a diferencia de lo que pasaba con las grandes ciudades. Por lo que se refiere a los griegos propiamente dichos, es difícil saber en cada caso si están presentes en la ciudad desde el principio o han llegado con posterioridad; a diferencia de lo que ocurre con los nombres macedonios, bastante frecuentes, los nombres griegos son escasos, aunque no inexistentes ${ }^{28}$; en ocasiones a partir de los nombres de tribus y de las monedas, puede llegar a afirmarse que el elemento griego remonta al momento de la fundación y la mayor cantidad de casos procede de Asia Menor ${ }^{29}$.

Un problema que planteó la utilización (preferente) de griegos y macedonios en las colonias Seléucidas fue la limitación de los recursos humanos en Grecia y, sobre todo, el corte definitivo de los mismos después del 188 a.C.; como se ha dicho, la mayor parte de las colonias se hallaba compuesta por soldados, bien en la reserva, bien licenciados, asentados en grupo sobre tierras otorgadas por el rey ${ }^{30}$. La paz de Apamea, del 188 a.C. prohibía a Antíoco III reclutar soldados dentro del área de influencia romana (Polibio, XXI, 43; Livio, XXXVIII, 38; Apiano, Siria, 39) lo que significó, por lo tanto, el final de la disponibilidad de reclutas helénicos aun cuando no queda tan clara la cuestión de los colonos, llamémosles

28 Cf. Ibidem, pág. 31 que menciona Herea, Tegea, Cálcide, Acaya, Calípolis, Maronea y Perinto.

29 TSCHERIKOWER, V., Op. cit, págs. 199-203.

30 COHEN, G.M., Op. cit, pág. 29. 
"civiles" ${ }^{31}$; los datos estadísticos elaborados por Launey muestran que a lo largo del siglo III se mantiene aceptablemente alta la proporción de soldados griegos, que decrece bruscamente a partir del 200 a.C.; los macedonios, sin embargo, se mantienen, aunque no proceden de la emigración, sino de las colonias militares ${ }^{32}$.

Solía preferirse, por razones de seguridad y estabilidad social, a grupos homogéneos y, casi siempre, las colonias eran designadas por la nacionalidad de sus componentes, lo que sugiere un cierto grado de uniformidad; así, por ejemplo, Larisa de Siria fue poblada por jinetes de Larisa en Grecia (Diodoro, XXXIII, 4 a), Pela (ulteriormente Apamea) en Siria fue llamada así porque sus primeros habitantes eran macedonios (Estrabón, $\mathrm{XVI}, 2,10)^{33}$.

Un problema importante es el de las tierras que eran repartidas a los colonos; es difícil saber en muchos casos si dichas tierras procedían de la confiscación a eventuales ocupantes anteriores o si, por el contrario, se trataba de parcelas de tierra real desocupada, entregada a los colonos ${ }^{34}$; en cualquier caso, parece que era el gobernador provincial el que recibía el encargo directo de tomar las medidas necesarias para que la fundación pudiese llevarse a cabo. También plantea problemas la cuestión de la mano de obra para poner en cultivo los kleroi; puesto que buena parte de los colonos era personal militar, es posible que necesitasen ayuda, sobre todo en los primeros momentos de la colonia y, muy especialmente, cuando se hallasen fuera de la misma; en todo caso, se sabe que los ejércitos helenísticos marchaban con una gran comitiva, en la que se incluía no sólo a mujeres y niños sino también esclavos; es muy posible que muchos de estos dependientes acompañasen a sus amos a sus nuevos lugares de residencia; además, estaba la población local, aunque no se sabe muy bien qué uso se hacía de estos campesinos locales, laoi. La finalidad básica de todo asentamiento, fuese urbano o rural, era asegurar la presencia Seléucida en alguna determinada región o territorio con algún fin concreto: protección de rutas de comunicación, reforzar zonas fronterizas o pacificar regiones rebeldes; la mayor parte de las colonias se fundaron en o cerca de alguna ciudad o población indígena ${ }^{35}$.

31 BRIANT, P. “Colonisation helléristique et populations indigènes: la phase d'installation», Klio, núm. 60, (1978), pág. 97, quien afirmia que «ninguna cláusula del tratado de Apamea impedía la llegada de colonos a las ciudades Seléucidas de Siria».

32 LaUneY, M., Op. cit., t. I, pág. 103.

33 CoHEN, G.M. , Op. cit., págs. 30-31.

34 Cohen,, G.M., Op. cit, pág. 21 se inclina a creer más factible la segunda posibilidad.

35 Ibidem, págs. 23-25. 
Los nuevos colonos se hallaban ya organizados en diferentes unidades, habían demostrado su lealtad hacia los Seléucidas y se hallaban interesados en recibir tierras; estos elementos eran suficientes para convencer a los Seléucidas, igual que anteriormente a Alejandro Magno, de utilizar a estos individuos para fundar sus colonias; los veteranos conservaban, dentro de la ciudad, su organización militar con fines oficiales, como cuando votaban resoluciones o decretos; esto además permitía una movilización más fácil en tiempo de guerra ${ }^{36}$; la existencia de asociaciones de soldados, que garantizaban una estrecha cohesión entre ellos pudo constituir un importante vehiculo a la hora de establecer una colonia militar; estas asociaciones seguramente perduraron en muchos casos una vez que se había producido el asentamiento y aportaron a sus miembros vínculos sociales y fraternales así como una estructura política básica ${ }^{37}$. Sin embargo, en el Imperio Seléucida y a diferencia de lo que ocurría en Egipto, no hay pruebas sólidas de que como contrapartida a la entrega del kleros el colono tuviese obligaciones militares precisas ${ }^{38}$; sin embargo, el valor militar de la colonia quedaba asegurado por su guarnición y su plaza fuerte, inexpugnable; la población griega puede encerrarse en la misma en caso de invasión y constituir puntos de apoyo extraordinarios que configuran el armazón militar del país. Naturalmente, esos establecimientos aportaban soldados al ejército y se sabe que la mayor parte de los macedonios de los ejércitos Seléucidas provenían de las colonias establecidas en Asia Menor y en Siria ${ }^{39}$.

Una equitativa distribución del kleros fue una de las principales preocupaciones de los Seléucidas, y seguramente se evaluaban todas las características del terreno, su fertilidad, ubicación, orientación y proximidad con respecto a la ciudad; además se prevería la llegada de ulteriores colonos que, a cambio de recibir sus lotes más lejos de la ciudad tendrian derecho a que fuesen mayores; es posible que en las colonias militares la distribución de los kleroi se basase en el estatus alcanzado en el ejército y en los años de servicio; además, seguramente también jugaba su papel el momento de llegada del nuevo colono ${ }^{40}$.

Cuando una colonia modificaba su estatus por el de ciudad seguramente ello implicaba determinados beneficios, entre ellos posiblemente el

\footnotetext{
Ibidem, pág. 5.

Ibidem, págs. 76-77.

Ibidem, págs. 51-52.

Launey, M., Op. cit., t. I, pág. 53.

COHEN, G.M., Op. cit., pág. 63.
} 
de poder disponer libremente de su territorio ${ }^{41}$ que pasaba de ser chora basilike a convertirse en chora politike; es posible que el incremento de población fuese el factor determinante para el paso de colonia a ciudad; en ese momento seguramente se ampliarían sus fortificaciones. Una ciudad necesitaba nuevas instituciones al tiempo que la inclusión de la población ampliada, magistrados, tribus y, sobre todo, indígenas que en raras ocasiones eran ciudadanos de pleno derecho y que, más bien, se organizarían en politeumata, que consagrarían su separación del elemento grecomacedonio manteniendo a la ciudad como polis Hellenis ${ }^{42}$.

Junto a macedonios y griegos, e igual que en las colonias de Alejandro, el tercer elemento lo componían los indígenas o, en general, los no griegos. Además de los habitantes de los lugares en que se localizaban las ciudades, el propio ejército favorecía la mezcla de individuos de distintos orígenes; así, los reyes no sólo utilizaban macedonios, sino también tracios, misios y paflagonios como soldados y posteriormente los establecian en katoikías; en el ejército de Eumenes de Cardia ya había soldados tracios procedentes de las katoikias (Diodoro, XIX, 27, 5), quizá de Media, Partia o Sogdiana; los Tralleis, tracios, figuran como mercenarios en el ejército de los Atálidas; los dinastas de Pérgamo utilizan misios y Polibio informa de la existencia de katoikias misias $(V, 77,7){ }^{43}$; todo ello, por no entrar en la cuestión de las colonias militares formadas por judíos (Josefo, Antigüedades Judias, XII, 147-152) ${ }^{44}$.

Parece que el sistema habitual constitía en instalar primero a los griegos y, una vez hecho esto, trasladar a los indígenas, generalmente de las proximidades, que iban a ser asentados en la colonia; no parecía conveniente instalar simultáneamente a los dos grupos ${ }^{45}$.

Pero esto eran gotas de agua comparado con la inmensidad del mundo indígena en el que se desarrollan los asentamientos griegos; no obstante, lo que parece fuera de duda es que las fundaciones Seléucidas se mantuvieron como centros griegos durante varios siglos, lo que sugiere que debió de haber sistemas para preservar la identidad helénica en medio de un denso ambiente indígena; se ha sugerido que los soldados y exsoldados que componian la población de la nueva colonia irian a la misma acompañados de sus mujeres e hijos, tal y como era frecuente durante

41 Ibidem, pág. 40.

42 Ibidem, págs. 84-86.

43 Tscherikower, V., Op. cit., págs. 203-204.

44 CoHen, G.M., Op. cit, págs. 5-9.

45 Ibidem, págs. 38-39. 


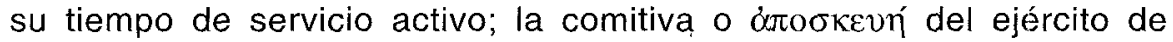
Alejandro era más del doble de la cifra de combatientes; Polieno (IV, 6, 13) da esta descripción del ejército de Éumenes en el 317 a.C.: «Antígono, sabedor de que a los soldados de Éumenes les seguía el bagaje, en donde se encontraban sus mujeres, hijos, concubinas, esclavos, oro, plata y otros bienes que consiguieron de la expedición con Alejandro, ordenó a escuadrones escogidos que trajeran los bagajes a su campamento". Sin embargo, también parece fuera de duda que algunas, o muchas de las mujeres con las que se casaban los colonos antes y después de asentarles en las colonias eran de origen indígena; Justino informa que esta práctica, que ya se da en época de Alejandro, continúa con sus sucesores: "Pero para que no pareciese que él sólo [sc. Alejandro] era el que cedía a los vicios de aquellos a quienes habia sometido por las armas, permitió a sus soldados que se casasen con aquellas cautivas con las que habían establecido relaciones, pensando que tendrían menos deseos de regresar a la patria si poseían en el campamento una imagen de sus lares y de su hogar doméstico; al mismo tiempo consideraba que las delicias del matrimonio mitigarían los sufrimientos de la guerra. Además, pensaba que para mantener sus efectivos agotaría menos a Macedonia si los veteranos, una vez convertidos en padres, fuesen sucedidos por sus hijos como reclutas en el destacamento en el que hubiesen nacido, y que estarían tanto más vinculados a su deber cuanto que el campamento habría sido para ellos no sólo una escuela, sino su propia cuna. Esta costumbre permaneció también entre los sucesores de Alejandro" (Justino, XII, 4, 2-7).

En cualquiera de los casos, y como afirma Cohen, «la influencia griega fue probablemente tan fuerte que marcó el carácter de la colonia, independientemente de quiénes fuesen las esposas de los colonos" ${ }^{46}$; la permanencia de las costumbres y formas de ser griegas se aseguraban mediante una serie de instituciones religiosas y, sobre todo, sociales, que estaban cerradas a los indígenas del entorno; de entre ellas la más importante era el gimnasio y todas las colonias, seguramente, dispusieron desde el inicio de uno; en él, además del ejercicio físico, a menudo de carácter paramilitar, se daban conferencias y había bibliotecas; en época de guerra sus terrenos podían ser utilizados para la instrucción militar; además, era un lugar de concentración pública y era importante como lugar de celebración del culto real; por fin, sirvió para separar a los griegos de los no griegos y así mantener la integridad demográfica de la colonia ${ }^{47}$. A

\footnotetext{
lbidem, págs. 34-35.

47 Para COHEN G.M., Op. cit., pág. 36, «el gimnasio se convirtió tanto en la reserva de la cul-
} 
ello habría que añadir, naturalmente, la lengua griega común y la conciencia de la identidad cultural así como unas estructuras políticas, basadas en el modelo de la polis clásica, que aun cuando tuteladas por los monarcas, garantizaban el autogobierno y la preeminencia helénica hasta en los lugares más remotos del Asia helenística ${ }^{48}$.

Ello, empero, no siempre parece haberse conseguido o, al menos, no siempre se ha reconocido; a propósito de la colonización militar macedonia Launey ha insistido en "cuán vulnerable era un pequeño grupo de macedonios aislados, sin contactos con el resto del mundo greco-macedonio, perdidos en el seno de una masa de orientales emprendedores y hábiles. Incluso si los descendientes de guarniciones y de colonias primitivas supieron salvaguardar su lengua de adopción, el griego, su nombre, una parte de sus tradiciones, y mantener la fiereza de su raza, la vida les ofrecía demasiadas ocasiones de abandono como para que estos bienes permaneciesen largo tiempo intactos: un matrimonio mixto, un nombre doble griego y oriental, la adopción de un culto indígena, un género de vida material conforme al que tradiciones milenarias imponían a las gentes del país, y tantas otras traiciones fáciles, inevitables sobre todo para los macedonios, cuyo helenismo era reciente y superficial» ${ }^{49}$; es posible que su opinión sea demasiado radical, pero no podemos dejar de ver aquí los ecos del propio Tito Livio que pone en boca de Cn. Manlio Vulsón, en 189, las siguientes palabras, tampoco demasiado dignas de crédito por el contexto (una arenga) en el que son pronunciadas: "Los macedonios que se han ostablecido en Alejandría de Egipto, en Seleucia y en Babilonia y que han fundado otras colonias en las diversas partes del mundo, se han acabado convirtiendo en sirios, partos, egipcios» (Livio, XXXVIII, 17, 10).

\subsection{Los Lágidas}

El caso del Egipto Lágida es bastante distinto del del Imperio Seléucida; allí no se produjo una política a gran escala de fundaciones de

\footnotetext{
tura griega como en el campo de preparación para la vida social, política y militar del Oriente Helenísticom.

${ }_{48} C f$., por ejemplo, el caso de Aï Khanumi, una de las ciudades helenísticas más remotas, pero que conserva largo tiempo su carácter griego; sobre esta ciudad, en último lugar, RAPIN, C. "Greeks in Afghanistan: Aï Khanum» en Descoevdres, J.P. (Edit.), Greek Colonists and native populations. Procc. of the First Australian Congress of Classical Archaeology, Oxford, 1990, págs. 329-342.

49 LaUNEY, M., Op. cit., t. I, pág. 353. Sobre los prolemas de la "helenización», vid. en último lugar SHERWIN-WHITE,S.M.; KUHRT, A. From Samarkhand to Sardis. A new approach to the Seleucid Empire. Londres, Duckworth, 1993, págs. 141-187.
} 
ciudades; prescindiendo de la capital del reino, Alejandría, y de Tolemaide en el Alto Egipto, fundación del primero de los Tolomeos, los reyes Lágidas no prosiguieron esta política de construcción de ciudades; sin embargo, sí promovieron el establecimiento de asentamientos militares macedonios y repartieron tierras a clerucos griegos, pero no promovieron comunidades de tipo ciudadano. Además, había griegos viviendo en ciudades egipcias, ya desde antes de la época helenística, que eran llamadas con nombres griegos; sin embargo, estas ciudades no eran poleis en el sentido griego del término sino que siguieron siendo, como anteriormente, los centros administrativos desde los que se dirigían los nomos ${ }^{50}$,

Fuera de Egipto, sin embargo, los reyes Lágidas sí promovieron algunas fundaciones coloniales, tanto en Asia Menor como en las Islas así como en el Mar Rojo; en la mayor parte de los casos se trataba de puertos, dada la gran vocación marítima del estado egipcio, en lo que contrastaba fuertemente con lo que ocurría con las fundaciones de Alejandro, poco interesado por el mar tras la neutralización de la flota persa y la destrucción de Tiro y con las del imperio Seléucida, especialmente centradas en el interior del país. El tipo de estructura suele ser de tipo polis y documentación epigráfica correspondiente a las mismas menciona a sus magistrados, sus estructuras cívicas (boulé, gimnasio, etc). ${ }^{51}$. Sin embargo, ni la importancia de las fundaciones tolemaicas, ni su supervivencia, son equiparables a las de las fundaciones Seléucidas; para Cohen, la diferencia básica entre ellas radica en que para el Imperio Seléucida las colonias forman parte integral de su política interior, y eran un medio para mantener el control sobre su imperio, mientras que para los Tolomeos eran parte de su política exterior, centrada en gran medida en la necesidad de mantener el comercio exterior con el litoral oriental del Mediterráneo; las colonias tolemaicas servían como medio de mantener su talasocracia, lo que explica también lo poco que sobrevivieron tras su partida de la cuenca del Mediterráneo ${ }^{52}$.

50 TSCHERIKOWER,, V., Op. cit., págs. 182-183.

51 COHEN, G.M. «Colonization and population transfer in the hellenistic world» en Egypt and the hellenistic World, Lovaina, 1983, págs. 70-71: «En la costa del mar Rojo dos Arsinoes y Berenices así como una Tolemaide, Filotera y Ampelone se hallaban al servicio de las rutas marítimas del Mar Rojo - especialmente el tráfico en elefantes - y a la flota que las protegía. En el Meditérraneo oriental había una Arsinoe, Berenice y Tolemaide en la costa de Cirene. Desde luego, en la costa egipcia Alejandro habia hecho ya el trabajo de los Tolomeos. En Palestina Akko fue rebautizada Tolemaide. En la costa cilicia había una Arsinoe y una Berenice mientras que Panfilia, del mismo modo, tenía una Arsinoe así como una Tolemaide. En Licia, Patara fue renombrada Tolemaide, igual que Lébedos en Jonia. Habia también una Tolemaide en Caria, posiblemente cerca de Cauno. En Chipre habia tres Arsinoes, en Creta dos y en Ceos una, mientras que en la costa de la Argólide Metana fue renombrada también Arsinoe».

52 COHEN, G.M. Ibid, pág. 74. 
Cohen ha subrayado las diferencias entre la colonización tolemaica y la Seléucida: «mientras que éstos eran asentados juntos en muchas colonias recién organizadas, los colonos egipcios eran dispersados por todo el país, generalmente en aldeas indígenas ya existentes»; la razón, como ya avanzó Préaux seguramente radica en la ausencia o escasez de espacio habitable en Egipto ${ }^{53}$ sin olvidar que había también una fuerte tradición faraónica de realizar concesiones de tierras a la clase militar

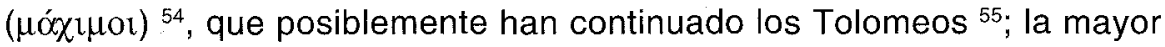
parte de los colonos originarios eran soldados, generalmente mercenarios griegos y extranjeros, dependiendo el tamaño del kleros de su posición en el ejército, y recibiendo un nombre adecuado a la cantidad de tierra percibida, medida en aruras [una arura equivale a 0,275 ha.]: triakontarouri, tessarakontarouri, hebdomekontarouri, etc.; las cantidades oscilaban entre las cinco aruras que recibía un soldado nativo (tras la batalla de Rafia) y las setenta o cien aruras que recibía un soldado de caballería; aunque el número de categorías y el tamaño de los kleroi se modificó con el tiempo, el principio esencial de relacionar el tamaño de la parcela con el cargo y categoría militar permaneció inalterado ${ }^{56}$. El nombre oficial que recibieron estos colonos era el de clerucos, aunque a lo largo del siglo II en la mayor parte de los documentos empezó a dárseles el nombre de katoikos ${ }^{57}$, reservándose el nombre de clerucos para los indígenas egipcios ${ }^{58}$.

La tierra que recibían los clerucos era tierra real distribuida por el rey a los colonos, y seguía siéndolo tras la entrega; podía revertir al trono a la muerte del ocupante, si no pagaba los impuestos correspondientes o si no ejecutaba sus deberes militares; sin embargo, lo habitual era que la tierra pasase de padres a hijos con la única condición de que el heredero siguiese cumpliendo las obligaciones militares asignadas al primer cleruco; con el tiempo las condiciones se fueron moderando y se dieron casos de arrendamiento de tierras, a cambio únicamente de que los impuestos siguiesen siendo pagados ${ }^{59}$. Además de la tierra, el cleruco recibía alojamiento, generalmente en casa de un indigena; eso era llamado stathmos, igualmente de propiedad real, aunque ulteriormente también se convirtió

\footnotetext{
COHEN, G.M., «The Seleucid colonies ...», pág. 53.

LAUNEY, M., Op. cit., t. I, pág. 45.

WINNICKI, J.K., «Die Ägypter und das Ptolemäerheer», Aegyptus, núm. 65, (1985), p. 50.

COHEN, G.M , «The Seleucid colonies ...», pág. 54.

LAUNEY, M., Op. cit., t. I, pág. 45.

WILL, E., Op. cit., pág. 49.

COHEN, G.M., «The Seleucid colonies ...», pág. 65.
} 
en propiedad individual, y fuente de conflicto permamente entre griegos y egipcios y entre griegos entre sí ${ }^{60}$. Las tierras concedidas estaban, por consiguiente, gravadas con todos los impuestos habituales y con algunos específicos de este tipo de tierra, aun cuando se tiende a creer que estas obligaciones fiscales eran más leves. Además, y sobre todo, el cleruco tenía obligaciones militares; eran movilizables en cualquier momento; según Launey "constituyen pues, en el marco de una monarquía, lo que más se asemeja a los soldados-ciudadanos de la vieja Grecia; se asemejan aún más a la población de la que la monarquía macedonia reclutaba sus soldados» ${ }^{61}$, observación que es válida al menos desde un punto de vista puramente formal, no estrictamente institucional.

La perduración del sistema, a lo largo del siglo III, queda garantizada por aportaciones externas; sin embargo su continuidad se aseguró básicamente por los deberes impuestos y los derechos reconocidos a sus descendientes, los epígonos; con este nombre se denomina a los hijos de los soldados, nacidos en Egipto y no indígenas, hasta el momento en el que ingresan en el ejército ${ }^{62}$. Sin embargo, en la batalla de Rafia (217 a.C.) Tolomeo IV tuvo que hacer un gran uso de soldados indígenas, lo que le reportaria problemas en un muy breve espacio de tiempo: «Inmediatamente después de estos sucesos, Tolomeo se vio obligado a guerrear contra sus propios súbditos. Este rey, en efecto, había armado a los egipcios para la guerra contra Antíoco [III: cuarta guerra siria]: tal determinación le resultó acertada para el presente, pero equivocada para el futuro. La victoria de Rafia ensoberbeció a aquellas gentes y ya no soportaron más la autoridad. Se creían capaces de bastarse a sí mismos y se buscaron un capitoste bien figurado, cosa que acabaron por lograr, y muy pronto" (Polibio, $\mathrm{V}$, $107,1-3)$. También en la famosa piedra de Rosetta, que contiene un decreto de los sacerdotes egipcios en honor de Tolomeo V, datado el 27 de marzo del 196 a.C., posiblemente sigue habiendo ecos de tales disturbios: «... y ha ordenado además que aquellos soldados [machimoi] que regresasen y aquellos otros que se rebelaron durante el período de disturbios pudiesen volver y tomar posesión de sus propiedades .... (OGIS, 90, II. 19-20). Parece fuera de dudas que la decisión de Tolomeo IV se debió a las dificultades crecientes de enrolar a griegos, ya procedentes del exterior, ya de las cleruquías.

60 LEWIS, N. Greeks in Ptolemaic Egypt. Case studies in the social history of the Hellenistic World. Oxford, 1986, págs. 23-24.

61 Launey, M., Op. cit, t. I, pág. 47.

62 Ibidem, págs. 48-49. 
Habría que destacar también la tendencia entre los clerucos griegos a abandonar sus alojamientos en el campo para reagruparse en las capitales de los nomos, dejando sus tierras arrendadas a indígenas, e intentando reconstruir en esos centros, relativamente urbanos, algunas de las instituciones habituales de las ciudades griegas, tales como gimnasios, asociaciones culturales, etc. ${ }^{63}$, por no mencionar la existencia de poblados con rasgos arquitectónicos genuinamente helénicos como puede ser el caso de Filadelfia, en el nomo arsinoita, con templos de tipo griego y, naturalmente, gimnasio ${ }^{64}$.

El gran centro de la colonización macedonia en Egipto se situó en el nomo arsinoita, en torno al lago del Fayum, drenado en parte en época tolemaica y abierto por lo tanto en esta época al cultivo y a su consiguiente reparto; el gran número de aldeas en la zona, con nombres como Tolemaide, Arsinoe, Berenice, etc., atestigua la fuerza de la colonización macedonia ${ }^{65}$. La documentación procedente del mismo ha proporcionado tantos nombres de soldados como el resto de Egipto ${ }^{66}$; a partir de ella se ha podido observar la egipcianización de algunas familias de la clase militar, especialmente a partir del siglo II, que parece haber sido completa, al menos en la onomástica y las costumbres, si es que no lo fue también en el estatus; por otro lado, hay otra razón que aproxima cada vez más a los colonos militares a los campesinos indígenas y es el hecho de que el ejército contiene cada vez más egipcios, machimoi; en su momento, la población militar de las aldeas está compuesta en una gran proporción, si no en su totalidad, de indígenas ${ }^{67}$.

No obstante, distintos tipos de documentación han transmitido un número, 6475, de katoikos que vivían en el nomo arsinoita en los tres primeros siglos d.C., y que eran propietarios de tierras katoikas y de ascendencia helénica; sus nombres son en su gran mayoría de origen griego, siendo poco abundantes los nombres egipcios helenizados; en los nombres femeninos los de origen egipcio son un poco más numerosos que entre los masculinos, pero siempre menos profusos que los griegos ${ }^{68}$.

En Kerkeosiris, el catastro de los años 119/8 a.C., muestra que de un total de 101 adjudicatarios de tierras clerúquicas, 35 llevan nombres griegos, 65 indígenas y uno con nombre doble, también egipcio; las formas

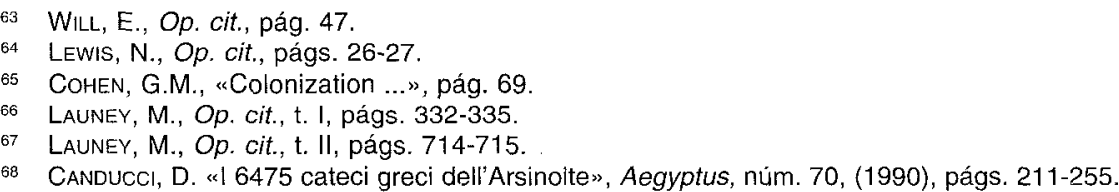


de vida, por ende, son prácticamente idénticas ${ }^{69}$. Para decirlo con las palabras de Launey, «en Egipto, la población indígena y los colonos militares llegaron poco a poco a establecer buenas relaciones, pero en la medida en que el heleno se acercó al indígena. No es, en efecto, el autóctono el que, seducido por la vida helénica, se eleva a su nivel, sino por el contrario el griego que, cada vez más diferente del griego de antaño, se fue convirtiendo poco a poco en más semejante al indígena: tan grande era el poder de asimilación de Egipto" ${ }^{70}$. Las apreciaciones de Launey están, sin embargo, desfasadas en parte y Will ha destacado cómo la posición del cleruco egipcio era en sí muy superior a la del campesino real, por más que fuese discriminatoria con relación a los katoikos griegos y también ha puesto de manifiesto cómo aquellos clerucos que conseguían acceder a la condición de katoikos, lo que implicaba un mayor lote de tierra y una cuantía menor en sus impuestos, tenderían «necesariamente a una cierta helenización, para justificar y reforzar su superioridad con relación a sus congéneres que no han accedido al estatus militar superior» 71 .

También a partir del catastro de Kerkeosiris, en el nomo arsinoita, se puede conocer la proporción de tierra clerúquica en comparación con la real, siendo la cantidad total de tierra cultivable de unas 4.700 aruras; resulta, merced a los datos conocidos, que la tierra real llegaba hasta el 52 $\%$ del total, la tierra clerúquica constituía el $33 \%$, las tierras propiedad de los templos un $6 \%$ y destinada a otros usos un $9 \%{ }^{72}$.

La documentación egipcia hace más hincapié en cuestiones de índole económica y social y deja ver la profunda interrelación entre griegos y nativos; se observa la aparición de nombres dobles, y el uso selectivo de los mismos según los contextos lo que acaso hable de la helenización de una porción de egipcios así como de una egipcianización de los griegos. No obstante, no insistiré más en estas cuestiones.

\section{CONCLUSIÓN}

Como conclusión de todo lo que venimos viendo hasta aquí podríamos retomar la idea que expresábamos al principio del artículo; la tierra fue un instrumento de primer orden en los intentos de los estados helenísticos

\footnotetext{
69 Launey, M., Op. cit, t. II, págs, 715-722.

lbidem, pág. 723.

WILL, E., Op. cit., págs. 49-50.

LEwIS, N., Op. cit, págs. 25-26.
} 
por conseguir un aprovisionamiento en soldados fiable y constante; mediante la instalación de antiguos soldados en tierras especialmente preparadas para esa función los reyes conseguían objetivos espectaculares:

En primer lugar, hacían patente la presencia del elemento políticamente dominante en los nuevos estados, en todos los rincones del mismo; los greco-macedonios y otros elementos helenófonos se hallaban instalados permanente en los centros vitales del vasto imperio Seléucida y un poco por todas partes en el siempre problemático Egipto.

En segundo lugar, e independientemente de las servidumbres militares de las tierras asignadas, más patentes en el caso egipcio que en el Seléucida, los establecimientos helénicos, fuesen simples colonias sin rango ciudadano, fuesen ciudades con plenos derechos, aportaban un contingente, siempre renovado, de soldados griegos a los ejércitos helenísticos, siempres hambrientos de recursos humanos.

En tercer lugar, y fuese o no una intención explícita de los monarcas Seléucidas y Lágidas, los establecimientos griegos sirven como medio de aproximaciones culturales de sumo interés, basadas bien en la coexistencia, codo con codo, de las poblaciones indígenas con los recién llegados griegos, bien en la práctica, seguramente intensa, de los matrimonios mixtos.

Junto a este «haber» de suma importancia histórica y cultural, sin embargo, es necesario destacar lo correspondiente al apartado del «debe», y que puede leerse como una especie de «negativo» de los tres puntos previos.

En primer lugar, el factor helénico es siempre intrusivo dentro de los contextos nativos en los que se inserta; su presencia implica expropiaciones de tierras y viviendas, desplazamientos de población, introducción de sistemas de cultivo y de gestión en parte novedosos, introducción de prácticas y formas del derecho griego, etc.; en suma, una dislocación de tradiciones arraigadas durante siglos.

En segundo lugar, el elemento helénico, a pesar de esta amplia labor, seguía siendo minoritario y, además, a partir sobre todo del siglo II a.C. los reyes se vieron en la necesidad de disponer, cada vez en mayor número, de tropas no griegas que, sin embargo, no recibían un trato en pie de igualdad con respecto a los soldados griegos, constituyendo esto un foco de tensión permanente, especialmente en Egipto.

En tercer término, y a pesar de los innegables intercambios culturales, los griegos se mantuvieron, o al menos lo intentaron, como un grupo cultural (que no étnico) cerrado, en el que no tenían cabida todos aquéllos (la gran masa de la población) que no eran, siquiera un poco, culturalmente helénicos.

Los estados helenísticos pudieron constituirse merced a los éxitos militares de Alejandro y su mantenimiento se debió, también en buena medida, a 
la existencia de un ejército leal; tierras para triunfar en la guerra, colonos que son soldados, son las claves del éxito de los reinos helenísticos. Hace poco más de cuarenta años, Launey concluía su magno estudio con unas consideraciones imbuidas de la mentalidad colonial de su época, hoy día ampliamente superadas y que actualmente resultan un poco naïves: "A los males fisiológicos que afectan a los europeos asentados bajo un cielo más cálido ... y que se traduce a la vez por una disminución de la fertilidad y por un incremento de la mortalidad infantil ... no era posible aportar remedio alguno ... Abandonados a su suerte, los Greco-Macedonios emigrados, afectados en su salud, su vitalidad y su fecundidad, expuestos a todas las alteraciones raciales que entrañaban los matrimonios mixtos, no cesaron de perder terreno. $Y$ habrían acabado perdiendo en todo caso, pero el proceso fue tanto más rápido cuanto que los propios indígenas contribuyeron al mismo" ${ }^{73}$. Ya no es momento de rebatir tales impresiones de Launey, pero sí mencionaré dos o tres hechos: los partos, que recibieron la mayor parte de la herencia territorial del Imperio Seléucida no hubieran podido estructurar su nuevo estado sin el imprescindible apoyo de los griegos de las ciudades que habían integrado en el mismo; los romanos fueron testigos, en la parte del Próximo Oriente que controlaron, del auge en sus días de las colonias griegas supervivientes y en Egipto permaneció un fortísimo componente cultural helénico hasta la irrupción del Islam. Pero dejemos que sea otro griego de Alejandría, Constantino Cavafis, quien resuma esta sensación:

\author{
«Y de esta sorprendente expedición panhelénica, \\ victoriosa, resplandeciente, \\ afamada, gloriosa \\ como ninguna otra lo fue, surgimos nosotros, \\ un nuevo mundo griego, inmenso. \\ Nosotros: alejandrinos, antioquenos, \\ Seléucidas y los otros \\ griegos incontables de Egipto y de Siria, \\ y los de Media y de Persia, y tantos otros. \\ Con estados enormes, \\ con la rica influencia de nuestra hábil adaptación. \\ Y nuestra Común Lengua Griega, \\ hasta el corazón de la Bactriana la llevamos, hasta la India» ${ }^{74}$.
}

\footnotetext{
73 LAUNEY, M., Op. cit., t. II, págs. 1089-1090. Puede verse un sugerente panorama de las nuevas perspectivas de estudio de las sociedades helenisticas en el reciente estudio de ALCOCK, S.E. «Breaking up the Hellenistic world: survey and society». I. Morris (ed.). Classical Greece: ancient histories and modern archaelogies. Cambridge, C.U.P., 1994, págs. 171-190.

74 CAVAFIS, C.P. «En el 200 a.C.» (1931). En Poesía completa. Edición de P. Bádenas. Madrid, 1982.
} 


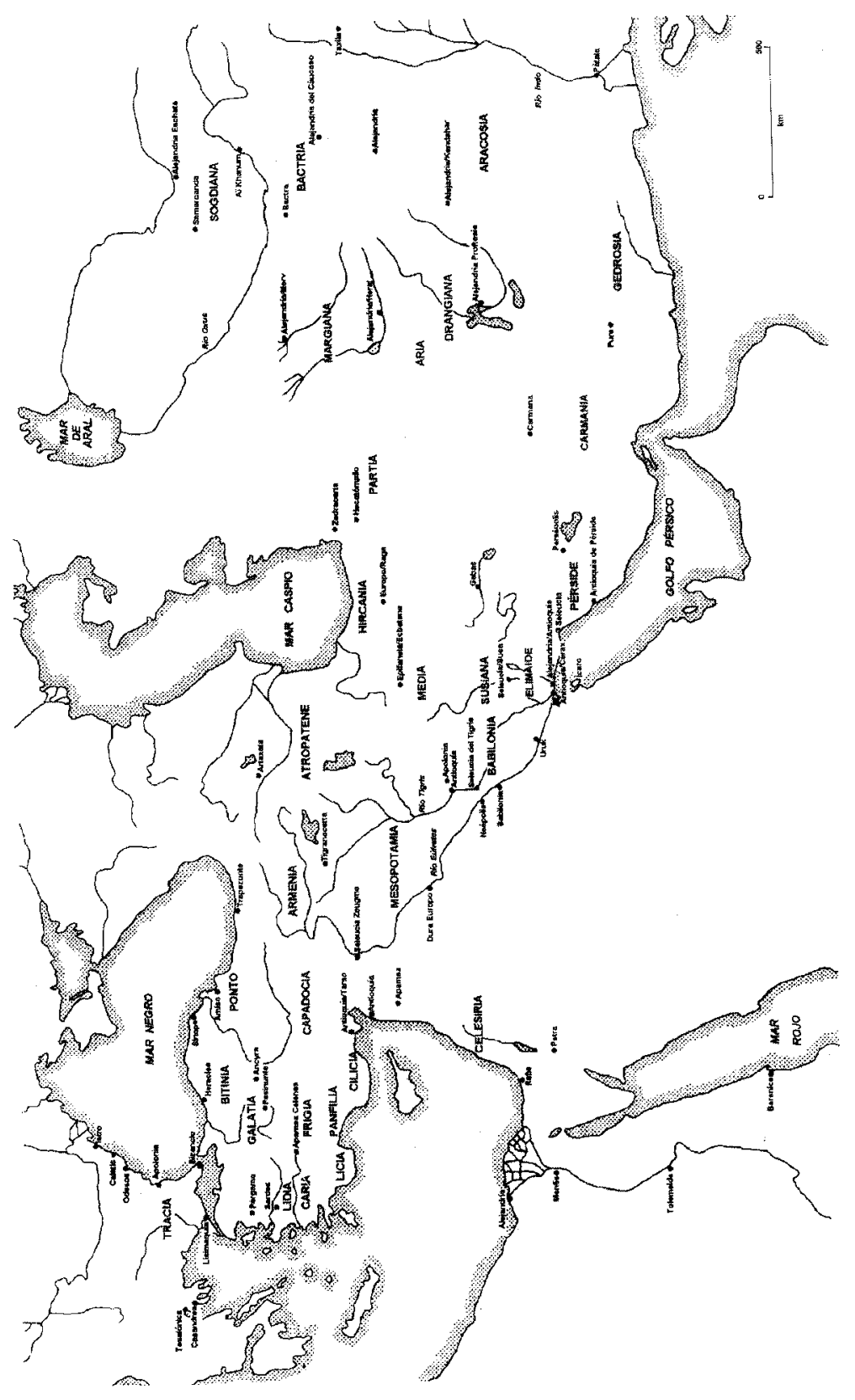

